\title{
Applying Self-Directed Learning Strategies on Reading Comprehension among Junior Secondary School Students in Offa Kwara State, Nigeria
}

\author{
Bello Yekeen ${ }^{1}$ \\ ${ }^{1}$ Arts Education Department, Faculty of Education, University of Ilorin, P.M.B. 1515, Nigeria \\ Correspondence: Bello Yekeen, University of Ilorin, P.M.B. 1515, Nigeria \\ Email: bello.y@unilorin.edu.ng
}

Doi: $10.23918 /$ ijsses.v8i2p118

\begin{abstract}
Andragogy which is the root of self-directed learning approach informs this study which aims to investigate the impact of SDL on learners' reading comprehension proficiency and the steps instructor can employ to instill SDL on learners. The study raised two research questions and one null hypothesis which were answered by using mean and standard derivation and the t-test statistical tool, respectively. One hundred (100) randomly selected samples that were divided into control and experimental groups were used. This was introduced so that learners concerns will be able to monitor their own learning. Reliability index of the instrument, having subjected them to validity process, was determined via test re-test statistical device which produced 0.66 reliability index at 0.05 alpha level of significance. The results reveal that there is a significant difference between mean scores of TDL who scored 11.9967 and SDL with a mean score of 21.9967. The findings of this study lead to the conclusion that even though TDL strategies applied to reading comprehension was high, the application of SDL strategy to reading comprehension was very high. This implies that when learners are exposed to SDL strategies, they will achieve a lot because they learn at their own pace which leads to self-exploration. Considering the findings and conclusion of this study it is therefore, recommended that language teachers should pay attention to students learning processes with regard to the value of the strategy training in the language class to enable students to learn more efficiently and become autonomous learners.
\end{abstract}

Keywords: Self-directed Learning, Andragogy, Teacher-directed Learning, Reading Comprehension, Scaffolding, Reciprocal Teaching

\section{Introduction}

Learners these days have lots of problems while reading texts, they are more concerned with just getting the main gist or correct answers to their academic problems than with more important proceed on how to get the answers. Students nowadays depend too much on dictionary for every unknown word, whereas they can overcome this over-dependence on dictionary by reading and underlining unknown words or phrases and use contextual clues to guess the general meaning of those unknown words or phrases, and when this is done, it basically implies that the students are "thinking about thinking" otherwise known as metacognition.

Received: April 20, 2021

Accepted: June 18, 2021

Yekeen, B. (2021). Applying Self-Directed Learning Strategies on Reading Comprehension among Junior Secondary School Students in Offa Kwara State, Nigeria. International Journal of Social Sciences \& Educational Studies, 8(2), 118-127. 
Bello (2011) posits that even though dictionaries are useful, they should not be used too often. Teachers should help learners to develop awareness about their own thinking and learning processes, and when this is done, they are creating in the learners the ability to think about the effectiveness of the strategy's students can employ in reaching the academic goals they have set. The use of metacognitive strategy of planning what is to be done, monitoring the progress, and evaluating the results are effective ways of helping students to take control of their own thought and feeling processes. Poor readers generally lack effective metacognitive strategies and as such have little awareness on how to approach reading for academic success, they also have deficiencies in the use of metacognitive strategies to monitor their understanding and progress in whatever texts they read, whereas successful second language (L2) learners ought to know how to employ appropriate strategies to enhance reading comprehension for academic excellence. Block (2004) posits that a metacognitive strategy in reading comprehension is required for academic success.

In furtherance of the above, metacognition is the readers' awareness, what he or she thinks about while reading, or what thinking processes he or she initiates to overcome literacy challenges or how a reader selects specific thinking processes to make meaning before, during and after reading. Learners who take the initiative in learning i.e. (pro-active learners) learn and discover more things and learn better than students who sit at the feet of the instructors passively waiting to be tutored, they are referred to as reactive learners or learners who learn at instructional level. In line with the above submission, Block (2004), Harmer (2007) Long (2012) posit that self-directed learning is the extent to which the learner maintains active control of his or her learning process. This implies that self-diverted learning enhances learners the strategies to make learning decisions and solve problems about their learning on their own without being told what to do at all times. It further means that learners are provided with strategies designed to help them process information effectively and to be self-confident, believing that they have the abilities to succeed academically, thus, making them more reflective about their thinking and learning processes.

\section{Literature Review}

Learning as human activity least needs manipulation by others and that most learning is not the result of instruction, it is rather the result of unhampered participation in a meaningful setting. Allwright (1979) in Harmer (2007) opines that Dick Allwright and his colleagues who had the task of improving the English language skills of students from overseas who were soon to study on postgraduate courses started to question the ways their teacher had been teaching, their teacher had asked students to study grammar, he had explained vocabulary and taught paragraph organisation. But it did not seem to be working and it did not "sound right". How would it be the learners' wonder, if they abandoned all that and instead devoted their efforts to exposing students to English and getting them to use it, particularly given that they were highly motivated to learn. By this, Allwright's hypothesis was "if the language teachers' activities are directed exclusively at involving the learners in solving communication problems in the target language, then language learning will take care of itself". Allwright submits that students were later given task to do outside the classroom which involved speaking and reading and based on the previous expository experience students were able to achieve a lot, even without the teachers' intervention they were able to carry out the task successful using metacognitive process.

Self-diverted learning (SDL) which had its roots in andragogy i.e. Adult Education, the word comes from Greek (andr) meaning "man" and (agogas) meaning "leader of", therefore, andragogy literally means 
teaching man whereas "pedagogy" means "leading children" is an approach that has been tried with learners in elementary and secondary schools, and that it is viewed as learners being responsible owners and managers of their own learning process; self- directed learning sees the significant role of motivation and volition in initiating, managing and maintaining learners' efforts. Motivation propels the decision to will and participation, and volition sustains the will to see task through to the end to achieve the set goal. SDL i.e., Self-directed learning integrates self-management, i.e., management of time, context, social setting, resources, and actions with self-monitoring, evaluating and regulating their cognitive learning processes. SDL in a way is a strategy that gradually but systematically shifts instruction process from the teachers to the learners in such a way that learners move and learn according to their own pace which leads to self-discovery, self-confidence, and full determination. Similarly, Kerka (2000) Antonio (2001) also lend their voice that SDL makes learners to have a great deal of independence in setting learning goals and deciding what is worth-while learning as well as how to approach the learning task within a stipulated time frame.

SDL encourages cluster/collaborative learning among peers thus challenging individuals to come out of their shells; SDL makes learners to demonstrate a greater awareness of their responsibility in making learning meaning through self-monitoring; SDL is to motivate, make persistent, independent, selfdisciplined, self-confident, and goal-oriented; SDL makes learners to be more effective, and as sociable beings. Corroborating the above, Antonio (2001), Merriam (2001) and Bello (2017) are of the view that SDL develops domain-specific knowledge as well as the ability to transfer conceptual knowledge to new situation. It also seeks to bridge the gap between school knowledge and real-world problems by considering the traditional "talk and chalk" instructional method that students are generally used to. Through SDL learners are able to identify and value their own discoveries, experiences and expressions as well as experiences of their peers through critical thinking of individual initiatives and a sense of selfworth.

In line with the above submission, it means that SDL makes learners "learn how to learn", how to perceive, and most importantly, it makes one more self-directing in many areas of life, it is a situational attribute, i.e., impermanent state of being dependent on the learners' competence, commitment, and confidence, thus leading to leadership training. Bello and Lawal (2012) also assert that SDL leads to self-discovery. However, depending on the philosophical orientation of the teacher, the goals of SDL vary tremendously as teachers grounded in a humanistic philosophy contend that SDL should have as its goal the development of the learners' capacity to self-directed learning, while some teachers in their personal responsibility orientation (PRO) model of self-directed learning, argue that human nature is "basically good in accepting responsibility for one's own learning” and being proactive to drive their model.

In another instance, Harmer (2007) is of the view that many theorists and researchers have wondered whether a student ability to learn things depends on whether or not he is ready to learn it. For instance, Pienemann (1998) suggests that reading can promote acquisition of knowledge if what we are teaching is close to the next form that would be acquired naturally in the learner's inter-language. Pienemann's teaching hypothesis suggests that if you try to teach students language before they are ready for it, i.e., if you go directly from stage 2 to stage 4 without passing through stage 3 , the students may always revert back to stage 2 , because they were not ready for stage 4 . 
All learning, including language, is mediated by social interaction and it is regarded "assisted performance," and this happens when someone with more knowledge - say a parent or a teacher, helps the learners to progress. This help is called "scaffolding", that is, a kind of supportive framework for the construction of knowledge, and the scaffolding is removed when the learners can appropriate the knowledge for themselves. Vigotsky (1962) in Bello and Lawal (2012) argues that a key element of successful scaffolding is that the learners can only benefit from it if they (the learners) are in the zone of proximal development (ZPD), in other words, if they are just getting to the stage above their own current level of knowledge where they are ready to learn the new thing with the assistance of others. Interestingly, this is also similar to Krashen's idea of “ $i+1$ ”. Krashen (1984) sees the successful acquisition of knowledge by students of a second language as being bound up with the nature of the language input they receive; the nature of the language input has to be comprehensible, even if it is slightly above their productive level. Krashen refers to it as comprehensible input " $i+1$ " (that is information the students already have plus the level up) and the students have to be introduced to it in a relaxed setting.

Education as we all know is to produce self-directed, life-long and skilful learners. Many educational practices in public schools do more to perpetuate dependency rather than create self-direction even though there is more than one way for imparting knowledge. However, with some exceptions, effective teaching is situational that is it varies in respect to learners. The teachers then begin to provide some key characteristics of a learner who can take responsibility for learning such as the ability to define one's own objectives, an awareness of how to use language materials effectively, careful organisation of time for learning and active process of learning strategies. Knowles (1975) and Bello (2017) see the teachers' role as that of a facilitator of learning and a procedural guide rather than being a teacher or content transmitter. Corroborating Knowles, Bello and Lawal (2015) contend that one of the most important tasks of the teacher is to raise students' awareness on their roles in learning. It is worth-while to engage students in discussions on topics from the self-directed learning readiness scale (SDLRS) such as: I know that I want to learn and that I am a learner, so if I want to learn something, I can, and I like to learn and to solve problems because I know that thinking hard can be fun". This self-evaluating exercise will have positive influence on learners' awareness.

Using SDL as an instructional strategy, there is usually the need to generate questions through the use of questions designed to help learners to become aware of what good readers do, and how to become one. Similarly, long (1999) in Kerka (2000) also postulates those questions such as "did you read better today than yesterday? Could you keep the ideas in your book straight in your mind? Were there words you did not know? How did you figure them out? These imply that teachers should scaffold learning by making learning visible, visible enough to enable the learners develop the ability to use them on their own.

To see learners participating in decision-making is a very crucial aspect in SDL approach, meaning that involving students in decisions concerning what is to be learned, when and how it should be learned and how it should be evaluated. This, therefore, suggests the importance of allowing learners to pursue their own interests with their own learning pace so that learning becomes 'studial'. Much as students should not be given total freedom, in furtherance with the above, Bello (2011 \& 2018) espouse that when writers are allowed to choose their own topics, they write more often, and they write longer pieces. Instructors who want to encourage SDL must free themselves from a pre-occupation with tracking and correcting errors in 
that it is seen as "ego threatening act". Kerka (2000) and Antonio (2001) advocate greater tolerance of uncertainty, and encourage risk-taking, as well as focusing on learners' strong points instead of focusing on his or her weaknesses, as it is often more beneficial for learners to achieve a few objectives of importance to them, that is, to fulfill all the objectives that are important to the teacher. This assertion implies that learners should be allowed to explore ideas through peer discussions, even without fully intact answers - a process that can yield new and valuable insight; allowing learners to pursue personal interests without the threat of formal evaluation, and that even if they make mistakes, the activities will sustain their interest, transcend frustration, and eventually break barriers to achievement. Pinter (2013) stresses the need for uninterrupted-sustained-silent-reading (USSR) as a possible way of accomplishing SDL objective in the reading classroom.

As children grow, they grow with an increasing desire for autonomy, and as such SDL fits learners of this class to enable them to harness that natural desire to help achieve meaningful learning experience that will last through adulthood. A schematic presentation of the usefulness of SDL as adopted from Bello (2017) is shown below:

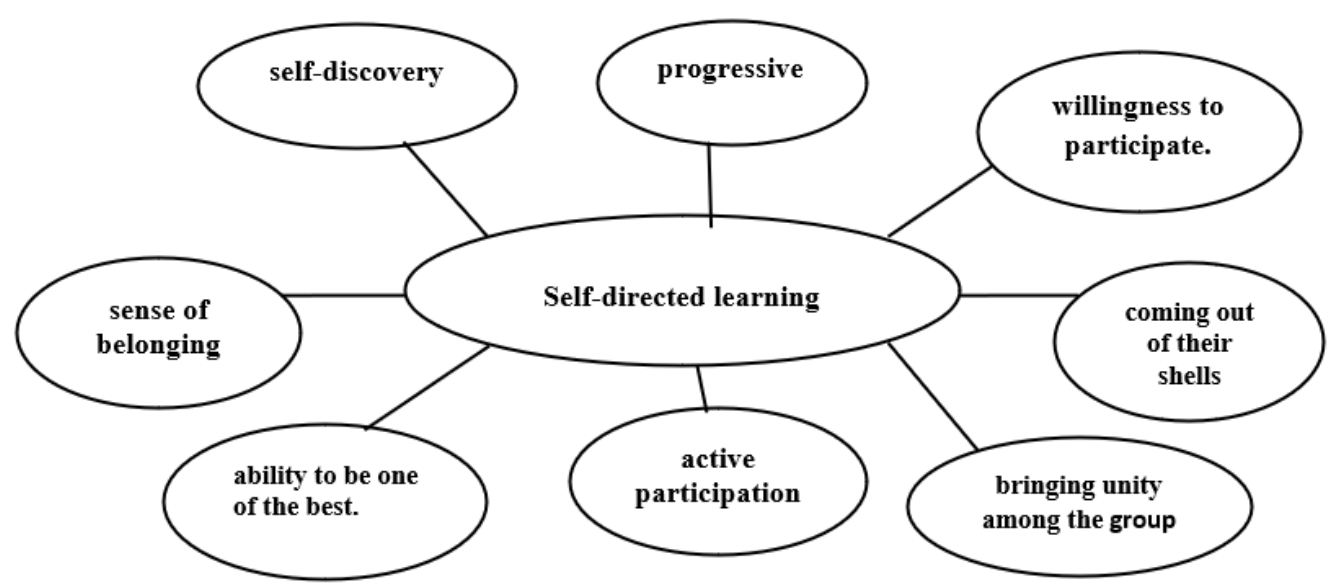

Figure 1: Researcher-designed benefits of learner-centred approach, adopted from Bello (2017) Cluster E-learning Teaching Method

Since SDL promotes self-discovery, confidence, and meaningful learning the language teacher must employ SDL strategies in delivery of his instruction. Reading comprehension as an academic exercise is the process that enables readers to construct meaning from the printed page most effectively. This shows how readers tackle a reading task, how they interpret their reading and what they do when certain words are not understood. Good readers, SDL by extension, draw on previous knowledge and experience to assist students understand what they are reading and are thus able to use that knowledge to make connections and a meaningful whole. SDL as a reading strategy enables learners to use clues contextually to advance in reading. Learners reading at instruction level needs instructor to assist them comprehend what they read, those reading at frustration level see no reasons for reading at all, but struggling readers often move through a text without stopping to consider whether the text makes sense based on their own background knowledge or whether their knowledge can be used to help them understand confusing or challenging 
materials. Pinter (2013) is of the view that when SDL is applied in the reading class, learners are able to think straight and develop self-confidence.

Since SDL stresses meaningful learning, a situated learning approach in which teachers bring real-life problems into the classroom for learners to work on but not one with 'sugar coated' work with fun, the rationale being that if the task is meaningful, learners will work on them willingly. Ajeigbe (2012) advocates that learner should be allowed to collaborate with their teachers to determine the time frame and other regulations if a worth-while learning is expected.

In another instance, reciprocal teaching (RT) as an instructional strategy for passing instruction in strategic reading was developed by Annermarie S. Palincsar which takes place in the form of a dialogue between teacher and students. In this strategy the teacher and the students take turns assuming the role of teacher in reading the dialogue about a passage in a text. Here, four strategies are used by the group members in the dialogue for reading comprehension, and they are: text prediction, summarisation, question generation and clarification of unknown or unclear content. In this, the real teacher is principally responsible initially and sustaining the dialogue through modeling and thinking out loud. As the dialogue progresses, the students acquire more practice with the dialogue in small groups, the teacher consciously shifts responsibility of the dialogue to the students, while becoming a coach to provide evaluative information and to prompt for more and higher levels of participation. This gradual, but deliberate and systematic shift from an instructor-centred approach to student-centred approach is a central component of the reciprocal teaching approach which encourages self-regulation on the part of the students, which is also similar to SDL.

\section{Statement of the Problem}

Strategies abound in teaching reading comprehension such as listen to the teacher, then read on your own and answer questions designed from it, reading one after the other in the class, and silent readings, are all noticeable features of learners' comprehension reading performance. Its place in the school curriculum cannot be overlooked as it determines the reading ability and interpretation of passages in texts. Most teachers of English language tactically ask learners to listen while they (the teachers read), then ask learners to read and ask questions based on the read passage without taking the students through the rubrics of reading internalisation and getting the gist through clues. Most teachers of English language get learners to study grammar and vocabulary, yet some of them make little attempt to allow learners to explore and discover themselves (Quezda 2018). This is so because most teachers see themselves as "all in all" thus believing that their learners could not do anything academically without a touch from the teachers. Gilbert (2008) and Bello \& Lawal (2012) are of the view that learners also rely on their teachers for virtually everything. Based on this, it is found that students have not been doing well in reading comprehension exercises due to the English teachers' traditional "talk and chalk" way of imparting knowledge. Even those students that are assumed to have been able to do fairly well in reading comprehension exercises, generally do not read effectively. As a result of this, several studies have been carried out on how to improve teaching reading comprehension. Dalton (2002) and Jerkins (2004) embark on research aimed at promoting the awareness of the larger roles of reading comprehension. Studies have been carried out on self-directed learning, but thus far, studies have not yet addressed the problem of reading comprehension using selfdirected learning as a strategy, this gap in research is what this study intends to fill. 


\section{Purpose of the Study}

The purpose of this study is to explore the application of SDL strategy on reading comprehension proficiency, students' accomplishments, and teachers' role in SDL.

Research Question

1. What is the achievement level of the students when teacher-directed learning strategy (TDL) was applied to their reading comprehension?

2. What is the achievement level of the students when SDL strategy was applied to their reading comprehension?

Research Hypothesis

Ho1: Self-directed learning strategies do not have any significant impact on learners' reading comprehension over teachers-directed strategies.

\section{Methodology}

The study is a survey carried out ex-post factor. The area covered in this study is Offa Local Government Area of the State. The population for the study comprised all the one hundred and eighteen JSS1-III students in Offa, Kwara. The sample for this study was selected through multi-stage stratified random sampling technique. By these 106 students of the entire population were divided into control and experiment groups, respectively. The control group trained in the conventional group in the conventional teacher-directed learning (TDL) strategies, while the experimental group trained and practised SDL reading comprehension strategies. The students, both in the control group i.e., teacher directed learning (TDL) strategies and the experimental group i.e., self-directed learning (SDL) strategies were assessed individually in reading comprehension texts before to harmonise, and after a long period of practice to see the impact of TDL and SDL. Comprehension passage texts were similar in both groups and in format of the questions and their level. The students were given 30 minutes to answer the questions. The questions consisted of 3 parts with a total of 15 questions: 5 items in parts A, B and C, respectively. In part A, learners were to choose the most suitable title; in part $\mathrm{B}$, learners were to answer multiple-choice questions while in part $\mathrm{C}$, learners were to choose true/false/no answer to conform to the questions asked by the read text.

\section{Data Analysis}

Research Question:

1. What is the achievement level of the students when TDL strategy was applied to their reading comprehensive? 
Table 1: The achievement level of the students when TDL strategy was applied to their reading comprehension

\begin{tabular}{|l|l|l|l|l|}
\hline Group & $\mathrm{N}$ & Mean & Standard Deviation & Decision \\
\hline TDL & 53 & 11.9967 & 1.00348 & High \\
\hline
\end{tabular}

2. What is the achievement level of the students when SDL strategy was applied to their reading comprehension?

Table 2: The achievement level of the students when SDL strategy was applied to their reading comprehension

\begin{tabular}{|l|l|c|l|l|}
\hline Group & $\mathrm{N}$ & Mean & Standard Deviation & Decision \\
\hline SDL & 53 & 21.9967 & 1.56958 & Very High \\
\hline
\end{tabular}

Research Hypothesis

Ho1: Self-directed learners' strategies do not have any significant impact on learners' reading comprehension over teacher-directed learning strategies.

Table 3: The t-test analysis of whether or not SDL strategies have impact on learners' reading comprehension over TDL strategies

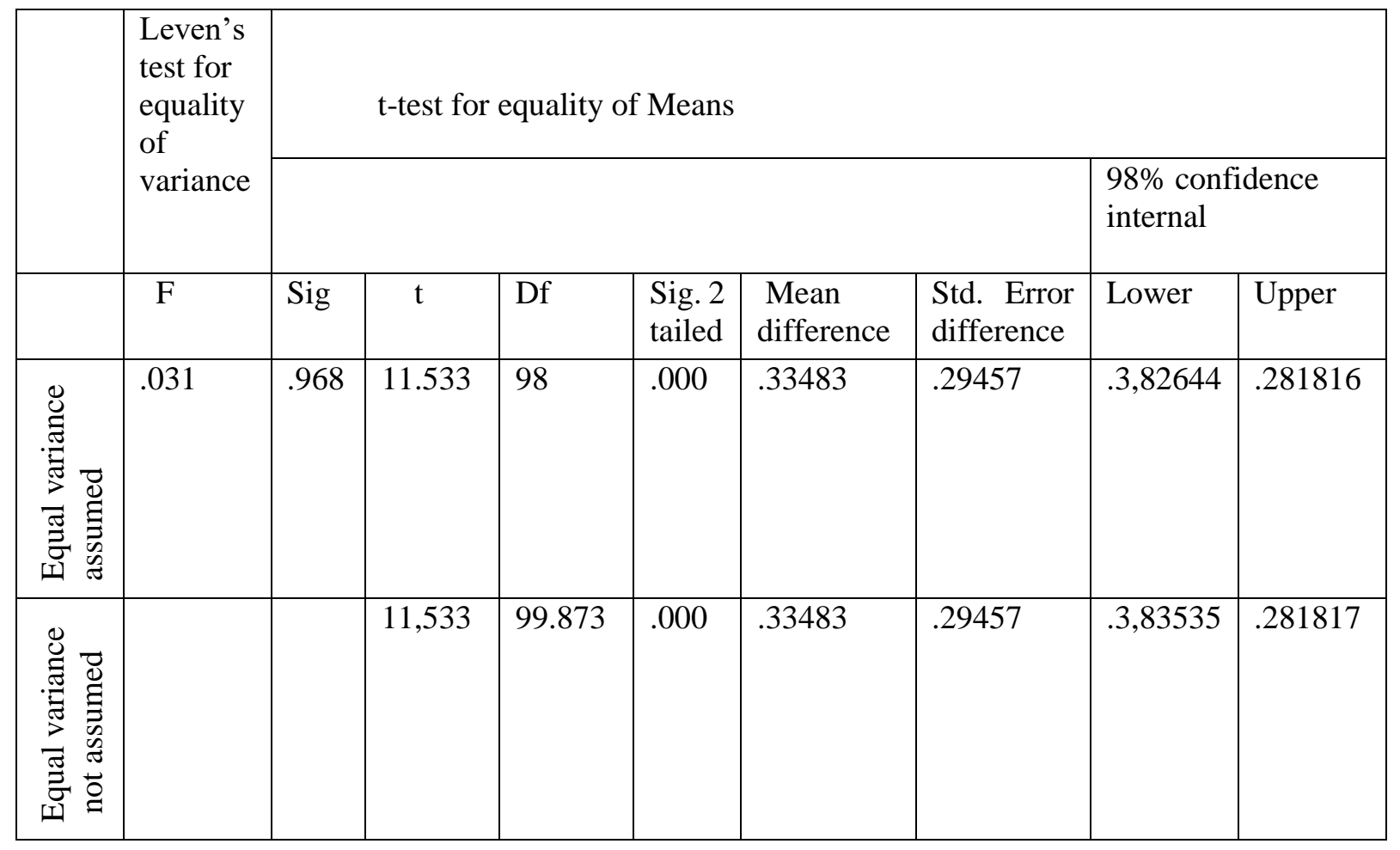




\section{Discussion}

Result of the analysis in table 1 shows that the achievement level of the students when TDL strategies was applied to reading comprehension was high with a Means score of 11.9967. This is in line with the finding of Pienemann (1998) who suggests that reading based on TDL can promote acquisition of knowledge especially if what you are teaching is close to the next form that would be acquired naturally in the readers' inter-language. Pienemann's "teachability" hypothesis suggests that if you try to teach students language before they are ready for it, i.e., if you go directly from stage 2 to stage 4 , without passing through stage 3 , the students may always revert back to stage 2 because they were not ready for stage 4 (implying that students need to be tutored stage by stage by the teacher).

Result in table 2 indicates that the achievement level of the students when SDL strategy was applied to reading comprehension was very high with a Mean score of 21.9967. This connotes the finding of Pinter (2013) who stresses that there is the need to allow learners to explore ideas through peer discussion, even without fully intact answer - a process that can yield new and valuable insights. Pinter states further that learner should be allowed to pursue personal interests without the threat of formal evaluation, and that even if they make mistakes, the activities will sustain their interest, transcend frustration, and eventually break barriers to achievement.

Result in table 3 shows the independent samples t-test and reveals a statistically reliable difference between the Mean score of TDL that has Mean of 11.99, standard deviation of 1.00, and SDL that has Mean of 21.99 and a standard deviation of $1.56, \mathrm{t}$ (98) of $11.53, \mathrm{P}=0.00$ at 0.05 alpha level of significance, thus rejecting the hypothesis that says that SDL strategies do not have any significant impact on learners' reading comprehension over teacher-directed learning strategies. This finding agrees with the submission of Bello (2017) who espouses that learners' participation in decision-making is a very crucial aspect in SDL approach. It also involves students in decision concerning what is to be learned, when and how it should be learned and how it should be evaluated. This suggests the importance of allowing learners to pursue their own interests with their own interests at their own learning pace so that learning becomes "stadial".

\section{Conclusion}

The findings of this study lead to the conclusion that even though TDL strategies applied to reading comprehension was high, the application of SDL strategy to reading comprehension was very high. This implies that when learners are exposed to SDL strategies, learners are able to acheive a lot because they move according to their own pace which eventually leads to self-exploration and discovery.

\section{Recommendations}

Considering the findings and conclusion of this study it is therefore recommended that language teachers should pay attention to students learning processes with regard to the value of the strategy training in the language class to enable students to learn more efficiently and become autonomous learners. 


\section{References}

Ajeigbe, J.A (2012). Reformed students' companion: redirecting the educated towards moral and academic excellence. Ilesa: Spirit and Life Books

Allwright, R. (1979). Language learning though communication practice. In Brumfit, C. \& Johnson, K. (eds). The communicative approach to language Teaching. Oxford: Oxford University Press.

Antonio, S. (2001). Self-directed Learning. Eric Digest, D. 169

Bello, Y. (2011). A speech delivered at the Science Students Orientation week at Literal University, Porto Novo: Republic of Benin.

Bello, Y., \& Lawal, A. (2012). An analysis of reading and comprehension performance of junior secondary school students in Offa, Kwara State, Nigeria. Aspects of language Variation, Acquisition and Use. Festschrift for Prof. N.E Kwofie, University of Cape, Cape: Coast Press, Ghana.

Bello, Y., \& Lawal, A. (2015). Students' personality traits and performance correlates of high grades in senior school certificate English in Kwara State, Nigeria. Asia Pacific Journal of Education, Arts and Sciences, 2(3), 102-126.

Bello, Y. (2017). Effects of cluster e-learning teaching method on senior secondary school students' achievement in English language in Abuja Metropolis, Nigeria. Papers in English and Linguistics (PEL), 18 (3\&4), 100-119.

Bello, Y. (2018). The perception of Kwara State youths on the need for cultural studies in Nigeria. Nigeria Journal of Social Studies, xv (2), 23-33.

Block, C. (2004). Teaching comprehensions: The comprehensive process approach. Pearson Education, Inc. Texas Christian University.

Dalton, D. (2002). Some techniques for teaching pronunciation retired February 2012 from http://itesli:org/techniques/daltonpronouncation.htm/.

Harmer, J. (2007). The practice of English language teaching. Fourth Edition. Pearson Longman.

Jerkins, J. (2004). Research in Teaching Pronunciation and Intonation. Annual Review of Applied Linguistics, 24, $109-125$.

Kerka, S. (2000). Self-directed Learning. Myths and Realities, 3.

Gilbert, B.R. (2008). Teaching reading comprehension using prosody pyramid. Cambridge University Press, New York.

Knowles, M.S. (1975). Self-directed learning. New York Association press.

Krashen, S. (1984). The power of reading. Eaglewood. Co: libraries unlimited.

Long, M.H. (2012). Instructed inter-language development. In Beebe, L. (ed). Issues in second language acquisition: Multiple perspectives. Newbury House.

Merriam, S.B. (2001). Andragogy and self-directed learning: pillars of adult learning theory. New directions for adult and continuing education, 89, Jossey-Bass.

Pienemann, M. (1998). Determining the Influence of Instruction on L2 Speech Processing. AILA Review, $5(1)$.

Pinter, A. (2013). Teaching young language learners. Oxford: Oxford University Press.

Quezada, P.A. (2018). Teachers-student factors in teaching EFL. Iberian conference on information system and technologies. Retrieved from http://aduck.g.cloubleclick.net/PCS/click in February 2021. 